\title{
Transcranial Doppler(TCD)による重症頭部外傷治療の評価
}

\author{
重森 稔, 森山 匠, 徳富孝志, 菊池直美, \\ 西尾暢晃，原田克彦，倉本進賢 \\ 久留米大学医学部脳神経外科
}

\author{
Evaluation of Managements for Severe Head Injury \\ with Transcranial Doppler Ultrasound \\ Minoru SHIGEMORI, M.D., Takumi MORIYAMA, M.D., Takashi TOKUTOMI, M.D., \\ Naomi KIKUCHI, M.D., Nobuaki NISHIO, M.D., Katuhiko HARADA, M.D., \\ Shinken KURAMOTO, M.D. \\ Department of Neurosurgery, Kurume University School of Medicine
}

\begin{abstract}
The efficacy and limitation of several medical managements for raised intracranial pressure(ICP)were studied in 20 patients of severe head injury by use of transcranial Doppler(TCD) ultrasound. The effects of head elevation (horizontal, $15^{\circ}, 30^{\circ}$ and $45^{\circ}$ ), hyperventilation, barbiturate and the Sendai cocktail (20\% mannitol, phenytoin and viatmin E) were evaluated by measuring blood flow velocity in the middle cerebral artery (MCAFV), ICP, cerebral perfusion pressure (CPP) and cerebrovascular $\mathrm{CO}_{2}$ reactivity. The cerebrovascular $\mathrm{CO}_{2}$ reactivity was investigated by obtaining the $\mathrm{K}$ value in the modified Olesen's formula of cerebral blood flow calculation.

As the degree of head elevation was increased, there was a gradual decrease in CPP in association with the decrease of MCAFV in 10 patients examined. These changes in CPP and MCAFV were remarkable in patients with lower GCS scores compared to those with higher GCS scores. The K values examined in 9 patients was low when the patient's GCS score were 5 or less. But as the patients GCS scores improved, the K values returned to normal nearly values. Barbiturates and the Sendai cocktail failed to improve raised ICP and also failed to improve raised ICP and reduced MCAFV in all patients whoes MCAFV were as low as $30 \sim 40 \mathrm{~cm} / \mathrm{s}$ before these treatments.

These results indicate that noninvasive study with TCD ultrasound can provide valuable informations on optimal therapeutic measures in patients with severe head injury.
\end{abstract}

Key words: Transcranial Doppler, Severe head injury, Management, ICP.

\section{1.はじめに}

重症頭部外傷に対する非手術的治療法には多くの種類 があるが，いずれも頭蓋内圧 (ICP) の制御や脳循環，代 謝障害の改善を主目的としたものである。しかし，いず れの方法にも利点や欠点があり，それぞれの有用性や限
局についても未だ不明な点が多い1)-4).

今回筆者らは，現在広く臨床応用されている，頭部挙 上, 過呼吸療法, バルビタール療法, さらに脳虚血に対 して脳保護作用があるとされる仙台カクテル5゙について, Transcranial Doppler (TCD) 6)を用いてそれぞれの有 用性や限界についての評価を試みたので報告する。

干 830 久留米市旭町 67 久留米大学医学部脳神経外科 重森 稔

Minoru SHIGEMORI: Department of Neurosurgery, Kurume University School of Medicine, 67, Asahimachi, Kurume 830 
Table 1 Effect of head elevation on CPP and MCAFV.

\begin{tabular}{|c|c|c|c|c|c|c|c|}
\hline \multirow[b]{2}{*}{$\begin{array}{l}\text { Case } \\
\text { No. }\end{array}$} & & \multirow[b]{2}{*}{$\begin{array}{l}\text { GCS } \\
\text { Score }\end{array}$} & \multicolumn{2}{|c|}{ Study } & \multirow[b]{2}{*}{$\begin{array}{l}\text { GCS } \\
\text { Score }\end{array}$} & \multirow{2}{*}{$\begin{array}{l}\text { Second } \\
\text { Change of } \\
\text { CPP (mmHg) }\end{array}$} & \multirow{2}{*}{$\begin{array}{l}\text { Study } \\
\text { Reduction Rate } \\
\text { of MCAFV }(8)\end{array}$} \\
\hline & & & $\begin{array}{l}\text { Change of } \\
\text { CPP (mmHg) }\end{array}$ & $\begin{array}{l}\text { Reduction Rate } \\
\text { of MCAFV }(8)\end{array}$ & & & \\
\hline 1. & $\mathrm{CC}$ & 3 & -29 & 30 & 3 & -22 & 25 \\
\hline 2 . & $\mathrm{CC}$ & 3 & -24 & 18 & 3 & -12 & 22 \\
\hline 3. & $\mathrm{CC}$ & 3 & -17 & 16 & 3 & -4 & 35 \\
\hline 4. & $\mathrm{SDH}$ & 4 & -7 & 5.6 & 7 & +2 & 5.4 \\
\hline 5 . & $\mathrm{SDH}$ & 4 & -22 & 4.2 & 3 & -22 & 20 \\
\hline 6. & $\mathrm{SDH}$ & 5 & -20 & 5.4 & 13 & -1 & 5.5 \\
\hline 7. & $\mathrm{CC}$ & 5 & -14 & 28 & 10 & +3 & 5.0 \\
\hline 8. & $\mathrm{SDH}$ & 5 & -1 & 4.4 & 14 & -7 & 5.2 \\
\hline 9. & $\mathrm{SDH}$ & 6 & 0 & 5.0 & 12 & -6 & 5.0 \\
\hline \multirow[t]{2}{*}{10.} & $\mathrm{SDH}$ & 7 & 0 & 5.2 & 12 & +5 & 5.6 \\
\hline & & Mean : & -13.4 & 12.2 & & -6.4 & 13.4 \\
\hline
\end{tabular}

Reduction Rate of MCAFV in Healthy Adults $(n=25): 5.4 \pm 0.8 \%$

CC : Cerebral Contusion SDH : Acute Subdural Hematoma

\section{2. 対象亡方法}

当科で入院治療を行ない, 入院時の Glasgow Coma Scale (GCS) score が 8 以下であった 20 症例（平均 45 歳) を対象とした。 症例の内訳は, 急性硬膜下血腫 8 例, 脳内血腫 6 例, 脳挫傷 6 例で, 血腫例はいずれも血腫除 去術を行なっている.いずれも主病変側の硬膜外より ICP を連続記録 (Gaeltec 社製センサを使用) し，同時に モニタした体血圧から脳灌流圧 (CPP) を算出した。ま た，全例で EME 社製 TCD（TC 2-64）を使用して，両 側の中大脳動脈主幹部の血流速度 $(\mathrm{MCAFV})$ を経時的 に測定した。なお，測定時には日本光電社製炭酸ガスモ ニ夕 (OIR-7101) により end-tidal $\mathrm{CO}_{2}\left(\mathrm{PCO}_{2}\right)$ を記録 した. $\mathrm{MCAFV}$ 変化の指標として平均流速を用いたが, 1 時期に 5 回の $\mathrm{MCAFV}$ 測定值を求めその平均值を求 めた. なお, MCAFV の対照值は健常成人 50 名から得ら れた值 $67 \pm 13 \mathrm{~cm} / \mathrm{s}$ を使用した ${ }^{7}$.

各治療法の評価は, MCAFV 值のほか, ICP および $\mathrm{CPP}$ 変化を指標としたが, バルビタール療法と仙台カク テルは施行前後 30 分時の值を比較して検討した. 頭部挙 上は Tilt table にて頭部を $15^{\circ}, 30^{\circ}, 45^{\circ}$ 挙上した際の変 化について，10例において検討した。 なお，健常成人 25 名において頭位を $45^{\circ}$ 挙上させた場合の MCAFV值の変 化率は頭位挙上前を 100 とすると $5.4 \pm 0.08 \%$ の範囲
内の変動に止まっていた ${ }^{7)}$. 過呼吸療法については，9例 において Respiratorによって $\mathrm{PCO}_{2}$ を変化させた際の 脳血管の $\mathrm{CO}_{2}$ 反応性を検討することによって行なった。 つまり, Olesen $ら^{8)}$, Markwalder ら ${ }^{99} の$ 方法に準じて In $\% \mathrm{MCAFV}=\mathrm{K} \cdot \mathrm{PCO}_{2}+\mathrm{A}$ 式中の $\mathrm{K}$ 值を算出した。 こ の際, $\mathrm{PCO}_{2} 40 \mathrm{~mm} \mathrm{Hg}$ 時の $\mathrm{MCAFV}$ 值を $100 \%$ とし, $\mathrm{PCO}_{2}$ 変化時の $\mathrm{MCAFV}$ 值を\%で表示した。なお，対 照值として, 健常成人 50 名から得られた $K$ 值 $=0.033 \pm$ 0.007 を用いた ${ }^{7)}$. バルビタール療法は 5 例に行なった が, 薬剤の投与基準, 投与量, 投与方法はすでに報告し た方法に準じて行なった ${ }^{3)}$.また，仙台カクテルは 6 例に おいて, $20 \%$ mannitol $10 \mathrm{~m} \ell / \mathrm{kg}$, phenytoin $10 \mathrm{mg} / \mathrm{kg}$, vitamin $\mathrm{E} 10 \mathrm{mg} / \mathrm{kg}$ を 60 分で投与した5). 以上の症例は いずれも入院時より $20 \%$ mannitol の 分割投与（総 量 $500-600 \mathrm{ml} /$ day) を受けているが, 上記の各種治療中は 投与を中止している.

症例の転帰は受傷後 3 力月時に Glasgow Outcome Scale に従って判定したが, Good Recovery と Moderate Disability Good, Severe Disability と Vegetative State

\section{3. 結 果}

\section{3-1 頭位挙上の効果について}

頭位を $45^{\circ}$ 挙上時の $\mathrm{CPP}$ および $\mathrm{MCAFV}$ 值の変化に 


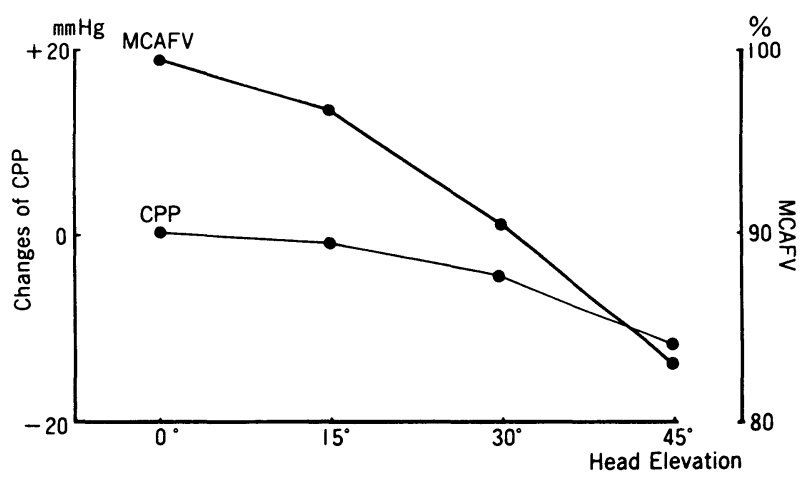

Fig. 1 Changes of CPP and MCAFV in head elevation (GCS of 3, 4, 5); Results of 12 trials in 8 patients (Casel $\sim 8$, Table 1) presenting mean values at each head-up position.

ついて, 10 症例で各々 2 回検討した結果を Table 1 に示 す。なお, 頭部挙上時の CPP の算出に際し, 頭部での血 圧は平均体血圧からモンロー氏孔までの hydrostatic pressure を差し引いた值を用いた。 2 回の検討時とも に, 症例の GCS score が 5 以下, 特に score 3,4 を示す 時点ではむしろ ICP の上昇，または血圧低下により CPP がむしろ低下した。そして, CPP 依存性に MCAFV 值が低下する所見が得られた。しかし，GCS score が 6 以上を示す時点ではCPPの低下度は軽度であり,

MCAFV の変化も健常人より得られた変動範囲内に止 まっていた（Table 1).

次に, GCS score が 5 以下を示した時点で頭部を $15^{\circ}$, $30^{\circ} ， 45^{\circ}$ 挙上した際の 12 回の検討結果をみると（Table 1), 水平仰臥位に比べ $30^{\circ}$ 以上の挙上時には $\mathrm{CPP}$ は平均 $12 \mathrm{~mm} \mathrm{Hg}$ 以上, $\mathrm{MCAFV}$ 值にも平均 $10 \%$ 以上の低下が 認められた Fig.1)。一方, GCS score 6 以上の時点での

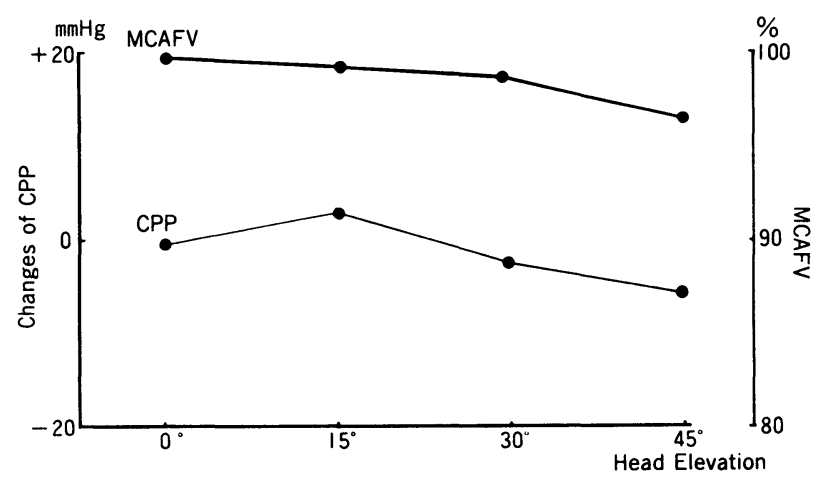

Fig. 2 Changes of CPP and MCAFV in head elevation (GCS of 6 12); Results of 8 trials in 6 patients (Case6 $\sim 10$, Table 1) presenting mean values at each head-up position.

8 回の検討結果では (Table 1), 頭部挙上に伴う CPP お よび MCAFV 值の変化率はごく軽度であった（Fig.2）。

\section{3-2 脳血管の $\mathrm{CO}_{2}$ 反応性について}

$\mathrm{K}$ 值からみた $\mathrm{CO}_{2}$ 反応性について, 9 症例で 2 回ずつ 検討した結果を Table 2 に示す. GCS score と K 值との 関係をみると, $\mathrm{K}$ 值は GCS score 上の悪化度や改善度に ほほ対応して変化していた。特に GCS score 3,4 の時点 では $\mathrm{K}$ 值が 0.018 以下と対照値に比べ著しい低值を示 した。しかし，GCS score が 6 以上に改善した時点で は，K 值はほぼ対照值の範囲内に止まっていた（Table 2). 次に, GCS score 5 以下を示した 5 症例において, end tidal $\mathrm{CO}_{2}$ 変化時の $\mathrm{MCAFV}$ の変化率をみると 健常成人に比べその変化はごく軽度であった（Fig.3）.

\section{3-3 バルビタール療法および仙台カクテルの効果について}

バルビタール療法を行なった 5 症例において本療法施 行前後の MCAFV と CPP 変化, さらに転帰について検
Table $2 \mathrm{CO}_{2}$ reactivity ( $\mathrm{K}$ value) and GCS scare.

\begin{tabular}{|c|c|c|c|c|c|c|c|}
\hline \multirow[b]{2}{*}{ Case } & \multirow[b]{2}{*}{ Diagnosis } & \multicolumn{3}{|c|}{ 1st study } & \multicolumn{3}{|c|}{ 2nd Study } \\
\hline & & GCS & Score & $\mathrm{K}$ value & GCS & Score & K value \\
\hline 1 & CC & & 3 & 0.011 & & 3 & 0.008 \\
\hline 2 & $\mathrm{SDH}$ & & 4 & 0.018 & & 7 & 0.027 \\
\hline 3 & $\mathrm{CC}$ & & 4 & 0.016 & & 3 & 0.014 \\
\hline 4 & $\mathrm{CC}$ & & 4 & 0.017 & & 3 & 0.011 \\
\hline 5 & CC & & 5 & 0.016 & & 10 & 0.017 \\
\hline 6 & $\mathrm{SDH}$ & & 5 & 0.018 & & 12 & 0.028 \\
\hline 7 & $\mathrm{CC}$ & & 5 & 0.027 & & 13 & 0.032 \\
\hline 8 & SDH & & 6 & 0.037 & & 12 & 0.035 \\
\hline 9 & SDH & & 7 & 0.033 & & 12 & 0.033 \\
\hline
\end{tabular}

$K$ value in Healthy Adults $(n=50): 0.033 \pm 0.007$

$\mathrm{CC}$ : Cerebral contusion

SDH: Acute subdural hematoma

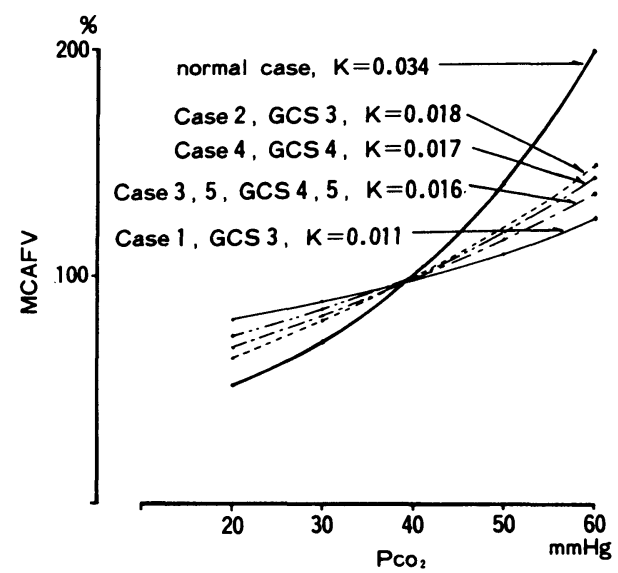

Fig. $3 \mathrm{CO}_{2}$ reactivity ( $\mathrm{K}$ value) in patients with low GCS score. 
Table 3 Changes of blood flow velocity in the middle cerebral artery (MCAFV) in barbiturate therapy.

\begin{tabular}{|c|c|c|c|c|c|c|c|c|}
\hline $\begin{array}{l}\text { Case } \\
\text { No. }\end{array}$ & $\begin{array}{c}\text { Age } \\
\text { (yrs) }\end{array}$ & Sex & $\begin{array}{l}\text { GCS } \\
\text { Score }\end{array}$ & $\begin{array}{l}\text { Response } \\
\text { to B-Therapy }\end{array}$ & $\begin{array}{l}\text { Hema toma } \\
\text { Side }\end{array}$ & $\operatorname{MCAFV}(\mathrm{cm} / \mathrm{sec})$ & $\begin{array}{l}\text { Change of } \\
\text { CPP (mmHg) }\end{array}$ & Outcome \\
\hline 1. & 52 & $M$ & 4 & + & $\begin{array}{l}\text { homo. } \\
\text { contra. }\end{array}$ & $\begin{array}{l}20 \longrightarrow 18 \\
46 \longrightarrow 53\end{array}$ & +32 & $\begin{array}{l}\text { Severe } \\
\text { Disability }\end{array}$ \\
\hline 2 . & 44 & M & 6 & + & $\begin{array}{l}\text { homo. } \\
\text { contra. }\end{array}$ & $\begin{array}{r}40 \longrightarrow 58 \\
100 \longrightarrow 110\end{array}$ & +28 & $\begin{array}{l}\text { Severe } \\
\text { Disability }\end{array}$ \\
\hline 3. & 40 & F & 5 & + & $\begin{array}{l}\text { homo. } \\
\text { contra. }\end{array}$ & $\begin{array}{l}16 \longrightarrow 60 \\
30 \longrightarrow 55\end{array}$ & +42 & Dead \\
\hline 4. & 70 & M & 6 & + & $\begin{array}{l}\text { homo. } \\
\text { contra. }\end{array}$ & $\begin{array}{l}28 \longrightarrow 22 \\
24 \longrightarrow 42\end{array}$ & +14 & Dead \\
\hline 5. & 17 & M & 3 & - & $\begin{array}{l}\text { homo. } \\
\text { contra. }\end{array}$ & $\begin{array}{l}16 \longrightarrow 6 \\
12 \longrightarrow 6\end{array}$ & -7 & Dead \\
\hline
\end{tabular}

MCAFV (Control : $67 \pm 13 \mathrm{~cm} / \mathrm{s}$ )

討した. 本療法に反応し, ICP 下降の得られた症例は 4 例であり,これらでは本療法後にCPPの増大と MCAFV 值の増加が認められた。 しかし，本療法施行前 に両側の MCAFVがいずれも $30 \mathrm{~cm} / \mathrm{s}$ 以下であった 3 症例はいずれも死亡した（Table 3).一方，仙台カクテ ル投与前後の MCAFV と ICP 変化についてみると, 本 剂投与後 MCAFV 值が増加し，ICP の低下がみられた のは 4 例であった.そしてこれら症例の投与前の平均 $\mathrm{MCAFV}$ 值は $65.5 \mathrm{~cm} / \mathrm{s}$ であり, 投与後平均 $13 \mathrm{~cm} / \mathrm{s}$ の 増加がみられた. しかし, 本剤投与前の MCAFV 值が 40 $\mathrm{cm} / \mathrm{s}$ であった 2 例ではいずれも MCAFV 増加や ICP 低
下は認められなかった（Table 4).

\section{4. 考察}

多くの重症頭部外傷例では ICP 上昇に伴い脳血流が 低下しており, $20 \mathrm{~mm} \mathrm{Hg}$ 以上の ICP 上昇時には死亡率や morbidity が明らかに高くなることは良く知られてい る ${ }^{1)}$.そこで ICP 上昇の制御や CPP の維持，さらに脳血 流改善のために多くの非手術的治療法が試みられている. しかし，いずれの方法もその有用性や限界が不明暸であ $り^{334)}$ ，治療法の選択に苦慮することが多い．そこで今 回, 頭部挙上, 過呼吸療法, バルビタール療法, さらに

Table 4 Effect of Sendai cocktail on MCAFV and ICP.

\begin{tabular}{|c|c|c|c|c|c|c|c|c|c|}
\hline $\begin{array}{l}\text { Case } \\
\text { No. }\end{array}$ & & Age & $\begin{array}{l}\text { GCS } \\
\text { Score }\end{array}$ & & $\begin{array}{r}\text { Before } \\
\operatorname{MCAFV}(\mathrm{cm} / \mathrm{sec})\end{array}$ & ICP $(\mathrm{mmHg})$ & $\begin{array}{c}\text { After } \\
\operatorname{MCAFV}(\mathrm{cm} / \mathrm{sec})\end{array}$ & ICP (mmHg) & Outcome \\
\hline 1 & SDH & 40 & 4 & & 90 & 40 & 102 & 30 & Good \\
\hline 2 & $\mathrm{CC}$ & 34 & 5 & & 50 & 28 & 60 & 18 & Good \\
\hline 3 & $\mathrm{ICH}$ & 16 & 5 & & 42 & 24 & 50 & 20 & Good \\
\hline \multirow[t]{3}{*}{4} & SDH & 44 & 6 & & 80 & 36 & 102 & 30 & Poor \\
\hline & & & \multicolumn{7}{|c|}{$----\cdots----\cdots-\cdots-\cdots$} \\
\hline & & & Mean & : & 65.5 & 32 & 78.5 & 24.5 & \\
\hline 5 & SDH & 68 & 4 & & 40 & 40 & 50 & 38 & Dead \\
\hline \multirow[t]{3}{*}{6} & SDH & 52 & 4 & & 20 & 24 & 20 & 20 & Dead \\
\hline & & & \multicolumn{7}{|c|}{$--------\cdots----------$} \\
\hline & & & Mean & : & 30 & 32 & 35 & 29 & \\
\hline
\end{tabular}


仙台カクテルの投与効果について, 主に TCD よる $\mathrm{MCAFV}$ 值の変化を指標としての評価を試みた。

TCD による MCAFV 測定の臨床的有用性については すでに多くの報告がある(6)10111). ICP と MCAFV との関 係について, 最近 Hassler ら ${ }^{10)}$ Saunders ら ${ }^{11)}$ は CPP と TCD による血流速度波形の変化との間に良好な相関関 係を認めたと報告している．また，筆者らの検討でも， $\mathrm{MCAFV}$ 值およびその $\mathrm{S} / \mathrm{D}$ が ICP 上昇や CPP 低下と ほぼ一定の関係で変化することを認めている7).したが って, 重症頭部外傷例で ICP 上昇に伴う頭蓋内血流動態 判定の 1 つの指標として，TCD による MCAFV 測定は 充分使用しうると思われる.

頭部挙上は頭蓋内からの静脈還流を改善し, ICPを低 下させる方法としてごく日常的に行なわれている. しか し最近, 頭部挙上によりむしろ CPP が低下し, ICP 上昇 を来すとする報告もみられる ${ }^{2122}$. 今回の検討の結果，い ずれの症例でも頭部挙上により CPP の改善や $\mathrm{MCAFV}$ の増加は認められず，水平仰臥位で最大の CPP が得ら れた。特に, GCS score が 3,4 という最重症例ではむし ろ CPP が低下し, CPP 依存性に MCAFV にも低下が認 められた。 そして, CPP 低下はICP の上昇または血圧の 低下のいずれかによるものであった，このことは，最重 症例では脳血流の autoregulation 機構がすでに破錠し ていることを示すと考えられる.したがって，これら症 例における頭位挙上は脳血流動態にとってはむしろ有害 である可能性があると思われる，そのため重症頭部外傷 例では頭位は少なくとも $30^{\circ}$ 以下に維持するほうがより 安全と考えられる。 な挹, 最重症例にみられた頭位挙上 に伴う ICP 上昇について, Rosner ら ${ }^{12)}$ は CPP 低下に反 応した頭蓋内血管の拡張に伴う脳内血液量増大をその原 因に求めている. また, 頭部での血圧低下については, cardiac preload低下に伴う心拍出量低下のためと推測 されている2121)が今後さらに検討が必要と思われる。

一方，過呼吸療法は脳血流を低下させることにより ICP をコントロールする方法であり, 脳血流増大が ICP 上昇の主因である症例では本法が有用と考えられてい る1). したがって，脳血流低下がすでに存在する症例や $\mathrm{CO}_{2}$ 反応性の障害例では本法は無効と思われる. 今回の 検討では， $\mathrm{K}$ 值からみた脳血管の $\mathrm{CO}_{2}$ 反応性は重症例ほ ど障害度が強いという結果が得られた. Markwalder ら 9 は脳血管の $\mathrm{CO}_{2}$ 反応性を TCD による血流速度測定 と脳血流測定の結果から比較し, 両者に直接の相関があ ることを証明している. また，TCDにより頭蓋内血流が low flow の状態か high flow の状態かの判定も可能で
ある7100111. したがって，TCDによる MCAFV 測定およ び K 值の算出によっても過呼吸療法の有用性の判断が 可能と思われ, 今回のごとく, 最重症例ではその効果に 疑問があるといえる。

以上のほか，今回は少数例ではあるがバルビタール療 法拉よび仙台カクテルについても検討を行なった。その 結果, これらの治療法開始前にすでに存在している脳循 環障害の程度がそれぞれの治療効果を規定していると考 えられた。すなわち, これらの治療法前にすでに $\mathrm{MCAFV}$ 值が $30 \sim 40 \mathrm{~cm} / \mathrm{s}$ 以下と著明に低下している場 合, ICP や CPP 変化, さらに MCAFV 增加率, 転帰か らみてこれら両治療法の有用性は否定的と思われた。筆 者らの以前の検討で，バルビタール療法の有用性が期待 できる限界は ICP $40 \mathrm{~mm} \mathrm{Hg}, \mathrm{CPP} 40 \mathrm{~mm} \mathrm{Hg}$ 前後であり, この両レベルを越えると MCAFV にも有意の低下が生 じることが判明している(3)7)したがって,これら治療法は 少なくとも高度の脳虚血状態に陥る以前に行なうべきと 思われる。

以上のごとく，TCDによる MCAFV 測定は重症頭部 外傷時の病態の検索7111)だけでなく, 各種治療法の評価に も充分利用しうると考えられた。

\section{文 献}

1) Miller JD. Significance and management of intracranial hypertension in head injury. In: Ishii S, Nagai $\mathrm{H}$, Brock M eds. Intracranial pressure V. Berlin: Springer-Verlag 1983 : 44-53.

2) Durward QJ, Amacher AL,Del Maestro RF, et al. Cerebral and cardiovascular responses to changes in head elevation in patients with intracranial hypertension. J Neurosurg $1983 ; 59: 938-44$.

3) 重森 稔, 川場知幸, 山本文人ほか。重症頭部外傷における術 後 Barbiturate 療法の効果と限界. 脳外 $1986 ; 14: 637-42$.

4) Eisenberg HM, Frankowski RF, Contant CF, et al. Highdose barbiturate control of elevated intracranial pressure in patients with severe herd injury. J Neurosurg $1988 ; 69: 15$ -23 .

5) Suzuki J. New brain protective agents and clinical case. In: Suzuki J ed. Advances in surgery for cerebral stroke. Tokyo: Springer-Verlag 1988:3-11.

6) Aaslid R, Markwalder TM, Nores H. Noninvasive transcranial Doppler ultrasound recording of flow velocity in basal cerebral arteries. J Neurosurg $1982 ; 57: 769-74$.

7) 森山 匠, 重森 稔, 松尾浩昌ほか. 重症頭部外傷に打ける中 大脳動脈血流速の変化. 神経外科 $1987 ; 10 ： 66-73$.

8) Olesen J, Paulson OB, Lassen NA. Regional cerebral blood flow in man determined by the initia lslope of the clearance of intra-arterially injected $133 \mathrm{Xe}$. Stroke $1971 ; 2: 519$ 40.

9) Markwalder TM, Grolimund P, Seiler RW, et al. Dependency of blood flow velocity in the middl ecerebral artery or end-tidal carbon dioxide partial pressure- $\mathrm{A}$ transcranial 
ultrasound Doppler study. J Cereb Blood Flow Metabol $1984 ; 3: 368-79$.

10) Hassler W, Steinmetz H, Gawlowski J. Transcranial Doppler ultrasonography in raised intracranial pressure and in intracranial circulatory arrest. J Neurosurg $1988 ; 68$ : $745-51$.
11) Saunders EW, Cledgett P. Intracranial blood velocity in head injury. A transcranial ultrasound Doppler study. Surg Neurol $1988: 29: 401-9$.

12) Rosner MJ, Coley IB. Cerebral perfusion pressure, and head elevation. J Neurosurg $1986 ; 65: 636-41$. 